ORIGINAL ARTICLE

\title{
Guesswork and guilt-the mind of a suicide
}

\author{
P Berry
}

J Med Ethics; Medical Humanities 2004;30:82-84. doi: 10.1136/jmh.2003.000165

This is an imagined dialogue between the ghost of a young suicide and an old schoolfriend. The living discussant, a doctor now, regrets that he did not realise how deeply troubled his friend was, and wants to know if and in what way he could have dissuaded the depressed schoolboy from his irrevocable decision. The ghost, however, confident in death, free from mental anguish, challenges the doctor's presumptions. What right does he, does society have, to stop, detain, dissuade, and "cure" those who wish to kill themselves? The issues of sanity, free will, and societal judgment are explored in an encounter that can never take place, but which sheds light on the thought processes of the suicidal.

$\mathrm{O}-\mathrm{a}$ ghost

$\mathrm{P}$-an old friend

O: A doctor! A psychiatrist?

P: No, nothing so grand...just a casualty officer at the moment.

O: You always knew what you wanted to be, I remember that. And now that you have met so many sad young things just like me-you want to explore what makes them tick. Haven't they explained themselves to you?

P: Not to my satisfaction. I can't challenge their perspectives too vigorously...I have to be delicate. But with you I can be more direct. You're at peace now, and you owe me an explanation. I'm too late of course, but had I known what you were planning to do...well who knows? Could I have stopped you? Could anyone?

O: I made very sure that no one was presented with that problem. I told nobody, I worked on my smile...I hid the torment well. But I did ask myself the questions that you and my family, even my doctor, might have asked, if my distress had been noted and my plan revealed.

P: Such as?

O: What of the consequences? The suffering I was to cause. By my wilful action I caused my family an eternity of guilt. Theirs has been a suffering more prolonged and bitter than ever I experienced.

P: So it was selfish? You accept that?

O: Totally. But those considerations paled

Correspondence to:

P Berry, Flat 2, 10 Carmalt Gardens, Putney, London, SW15 6NE, UK;

philaberry@hotmail.com

Accepted for publication 5 May 2004
Your mind, your illness had dragged you there. No choice.

O: That assumption neatly strips me of a defence. You would have felt justified in restraining me, regarding me as an irrational person, had you known my intentions. But you make a mistake in separating me from my illness. My depression was me. One can treat a failing organ, one can disown a tumour, reject it, but when the organ in question is that lump of matter that defines your very existence, there is no chance of distancing yourself. It is impossible to attain a perspective.

P: Couldn't you stand back, analyse the problem, and take some action? You were always so commonsensical.

O: Is that how you talk to your patients? Pull your socks up! But you're right-I had a degree of insight. How could I not notice my own deterioration? But my mood arose from within me. Events, I am sure, followed the mood. Did you know that I had plummeted academically, that my girlfriend, the one person I might have talked to, was fading from me? These things took on horrendous proportions, but correcting them would not have made me brighter. My mood was not compartmentalised. I lived under a leaden blanket.

P: I can see that there were no glimpses of light. But could not a small degree of interference have lifted a corner of that blanket? Another point of view might have helped you compare the awful present with a hopeful future.

O: But I cured myself, by dying. This need that you keep describing to me, this need for interference, reflects your guilt, so obviously. You remember the times, only days and weeks from my suicide, when we passed in the corridor. Your averted glance. You perceived the tip of my suffering, but could not fathom its depth. The guilt that you are experiencing is part of my awful legacy. You feel that those responsible for my welfare...my teachers, my parents, my friends, society as a whole, should have stopped what is by your standards the very worst outcome. For me it was the only satisfactory outcome. If no effort is made to stop the suicide, it reflects badly on society. If I had been stopped, you would not have suffered. But I would not have been saved. I would have been judged of unfit mind, and my suffering would have continued.

P: You would have received treatment.

O: Implicit in the word treatment is the process of rejecting the ill mind as aberrant. That process removes credibility from the patient's every utterance. His or her views, from that point onward, are listened to with the prejudiced ears of the doctor, who has made a diagnosis. 
P: So you are saying that you should not be perceived as ill, but as altered. That is so wrong. Can't you remember the time when you were not ill, before your depression set in. When you were carefree and even rebellious. That, surely, was the real you. If we had stopped you, even forcefully, and you had returned to your former state, you would have begun to enjoy life again. Your musical talents would have flowered. Life would have been as good for you as it is for any of us. No bed of roses, but more enjoyable than not.

O: More enjoyable than not. Is that the point of life? In my deepest moments I asked myself: why am I alive? Why am I here? Hackneyed questions. Dangerous questions, ones that the healthy mind is protected from by the necessities of everyday living. I had no God. I knew, as a scientist (at least of school boy standard!), that as a species in the universe we are insignificant and isolated, that all our creative efforts, including my music, will crumble in time, that our very existence is probably due to a chance occurrence in the primordial soup. All that I might have contributed to the world would have been forgotten or destroyed...so why live? Tell me?

P: I can't. Children perhaps...

O: Not a persuasive argument when one is dealing with a depressed adolescent. Can you not accept the possibility that those who kill themselves have perhaps achieved a higher wisdom? Perhaps they have taken a short cut. Perhaps they have recognised the futility. Why put up with a life that, as you admit, is sometimes painful, when it is all for nought?

P: Only some of us think like that. It is nihilistic in the extreme.

O: Most thinking people have grappled with these philosophical and depressing questions. You have.

$\mathrm{P}$ : Yes, and the result is not depression. I wake up in the morning, and, usually, foresee enough that is positive to sustain myself.

O: So what is it that allowed me to make the final decision, but which protects you? Is it a genetic difference, an inherent weakness? Is it an independence from the powerful social values that endow life with such sanctity? Or is it an ability to see clearly, and deal with the truth?

P: Your truth, you mean. There are many who recognise a different truth.

O: And that is the crux. The majority must be right. Mediocrity prevails, as it must. Any mind that does not reason according to the rules set by the standard and collective mind of society is, by definition, mistaken, and therefore deserving of interference.

P: That is paranoid.

O: Mildly, but not fantastically. If you see a person stray away from the norm, in such a way as to be a danger to himself, you label him ill. His autonomy is automatically negated. You then drag him back to the defined norm, within the bounds of acceptable and humane practice of course. You pull the mentally ill patient back from those areas of thought and feeling that are untrodden by the healthy majority. You give his unique experience no credence.

$\mathrm{P}$ : But he is suffering. We must try to alleviate that suffering. We must help restore to families a once useful and active father or mother, son or daughter. I have seen people recover from depression, and once again rejoin this society of mediocrity, as you call it.

$\mathrm{O}$ : You see. You are treating the patient, but what is motivating you? Is it pressure from the family that is now lopsided, from the parent that cannot understand how her child has become so changed, from the husband whose own life is made miserable by his wife's endless depression? Again, are you treating the patient, or the unit of society from which the patient has inexplicably veered?
P: We do not wrench patients back from some sort of enlightenment. We treat them, be it with drugs that alter the chemistry of the brain, or with simple communication, and they do not resent this interference. Patients do not bring back wisdom from their journeys. I have not seen people enlightened by these deeper, darker thoughts that you credit them with. You are making an assumption as large as that of which you accuse society. It is that all members of the population are capable of your level of intellectualisation. They are not.

$\mathrm{O}$ : The experience I am urging you to recognise in patients is not dependent on intelligence. It is you who make the mistake. If a patient describes to you, in an articulate way, their thoughts concerning their illness, you credit them with insight. This immediately lessens the severity of their illness in your eyes. If they have been able to retain society's perspective concerning themselves, you are less likely to assume superiority in making judgments. In those without insight, and in those without the education or language to assure you of insight, you feel justified in assuming superiority. You then feel justified, if there seems to be a risk of self harm, in removing their liberty. Would you have stopped me forcefully if I had reasoned like this on the way to the train track?

P: No, I couldn't have.

O: No, because I would have appeared of sound mind. Those, like me, who have suffered and who wish to die, may only be allowed to if they present a good argument, is that the case? Is that right? Only the intelligent can keep their autonomy. That cannot be right.

P: I have never encountered a suicidal patient who reasons as you have reasoned here.

O: That is irrelevant. They feel as I felt. They should not have to justify. If I can defend those feelings from interference by argument, you must respect what I defend and not the argument itself. Insight you see, may exist in silence, and in feelings only, not necessarily in words. Not everyone can talk as I do

P: The strength of your argument is based on your present comfort. You feel better now...so your act has been justified.

O: The fact that I released myself from torment should not weaken the substance of my arguments. You are trying to debase them, so that you can return to your hospital and remove your patients' liberty with a clear conscience. But I have shown you how they may be thinking, even if they cannot display their thoughts. That is why I have come to you...to impress upon you how wrong it is to assume a knowledge that you do not have. The successful suicide and the embarrassed, failed, suicide have explored chasms of thought into which you will hopefully never descend. You can only guess at their discoveries. To label such victims, to categorise that which you do not understand, may only belittle the memory of those who, however ill they may have been, took a personal decision.

\section{COMMENTARY}

Like many other people, whether or not they are medical students or doctors, I would like to know more of the thought processes of the suicidal. The imagined dialogue in Dr Berry's short paper succeeds admirably in illuminating some aspects of these thought processes, but while reading it I found myself wondering whether it was not slightly too simplistic. $†$

†I also found myself slightly uneasy about the amount of ad hominem arguments in the dialogue. Both the ghost and the old friend seem very happy to impute all kinds of problematic motives or beliefs to their interlocutor when they run out of good arguments. 
It is of course a good thing that the ghost is confident in death and has reached a situation without mental anguish, but did he also have this enormous insight before his suicide? Or was he like most of us, most of the time, somewhat muddled and confused? Is it really true of all suicides that "They feel as I felt"? Is the ghost giving us the truth about suicidal thought processes, or his own reworking of this truth? I fully accept that there are well considered suicides, embarked upon in a state of mental clarity and lucidity, but is that really the norm? Is not the most convincing interpretation of the quite significant literature concerning those who have unsuccessfully attempted suicide, that many attempt it on the spur of the moment?

Whatever we believe about suicide it seems problematic to think that all suicides share some common set of essential thought processes, especially when it is the case, as the ghost clearly realises, that many do not express that they have had these thought processes when asked. It may be the case that some or many have had these thought processes but are just unable or unwilling to express them, but there is some distance between this and the belief that they have all had them. What of those who vehemently deny having had them-are they mistaken about their own mind? If that is the claim, is the ghost not guilty of the same kind of problematic redescription of which he accuses his friend?

I was also wondering whether it is really the case, as it is implied in the dialogue, that none of those who attempt or contemplate suicide are really ill. If we assume a priori that mental illness does not exist this conclusion follows with ease, but what if we admit the possibility that mental illness may be a reality? In that case the arguments of the ghost are not all that convincing. Yes, it may be the case that doctors hugely overestimate the amount of illness among the suicidal, that they significantly underestimate the value of the suicidal and presuicidal experiences and so on and so forth, but this does not show that there are no, or only a few, cases of suicides attempted by people who are mentally ill (or whatever we want to call those states where people have thought patterns that they themselves wish to get rid of and see as strange).

In summary I think the dialogue does shed light on the thought processes of some of the suicidal, and points to the very real dangers of labelling them all as mentally deranged. I am still, however, left with the thought that there are other kinds of suicides who, even without the mental anguish they experienced in the hours before their suicide, would have quite a different message to give to their old friends.

My view on suicide has probably been shaped to a significant extent by one single episode I experienced as a young doctor in the accident and emergency department. A teenager was brought in after having tried to hang himself. He had called the police, telling them what he was going to do, and only jumped from the chair when the first policeman was through the door that the police had broken down. I leave it to the reader to consider to what extent this young man would have fitted the part of the ghost in the dialogue if he had succeeded in his suicide attempt.

S Holm

Cardiff Law School, PO Box 427, Cardiff CF10 3XJ, South Wales, UK: holms@cardiff.ac.uk 